Fecha de recepción: mayo 2021 Fecha de aceptación: junio 2021 Versión final: julio 2021

\section{De niñas, monjas y "malas". Figuras de la maternidad en el cine argentino del siglo XXI}

Marcela Visconti ${ }^{(1)}$

Resumen: Si a lo largo del siglo XX, el cine argentino despliega y sostiene un relato hegemónico de la maternidad según una concepción idealizada que organiza imaginarios, opera en los discursos institucionales y circula por la vida cotidiana, avanzado el nuevo milenio, una serie de ficciones y de documentales inscribe un giro en las formas de figuración de las madres, en el cual cobra visibilidad la especificidad del momento histórico. En sintonía con las ideas y los acontecimientos que construyen un presente desde la revuelta y la marea feministas que estallaron en Argentina en 2015, reorganizando la escena pública a partir de la visibilización de demandas políticas sobre el derecho de las mujeres a decidir sobre sus cuerpos, películas como Hogar (Maura Delpero, 2019); Niña mamá (Andrea Testa, 2019); Alanis (Anahí Berneri, 2017); Mi amiga del parque (Ana Katz, 2015); Mala madre (Amparo Aguilar, 2019); Desmadre, fragmentos de una relación (Sabrina Farji, 2018); Mamá, mamá, mamá (Sol Berruezo Pichon-Rivière, 2020); Las motitos (Inés Barrionuevo y Gabriela Vidal, 2020), entre otras, producen un desplazamiento, y problematizan, el relato tradicional que asimila a la mujer con la madre como único destino posible. ¿En qué momento y de qué forma, la revuelta continúa en expresiones creativas y sus formas de construir historias, de inventar figuras, de producir sentidos? A través del análisis de algunos de los ejemplos fílmicos mencionados, mi trabajo busca dar cuenta del ida y vuelta que tensiona las representaciones más allá de los bordes de la pantalla para imaginar nuevos "lugares de maternidad" (Domínguez 2007) que desacomodan los mandatos culturales al reinscribir la circulación del deseo, otras formas afectivas y el goce festivo de los cuerpos.

Palabras clave: maternidad - cine de mujeres - cine argentino contemporáneo - crítica fílmica feminista - marea verde.

[Resúmenes en inglés y portugués en la página 180]

(1) Doctora en Teoría e Historia de las Artes (UBA), magíster en Comunicación y Cultura (UBA) y licenciada en Artes (UBA). Se desempeña como profesora adjunta a cargo de la materia Análisis, Crítica y Estudios sobre Cine en la Facultad de Filosofía y Letras (UBA). Integra el Comité Editorial de Mora, revista del Instituto de Investigaciones en Estudios de Género (IIEGE) de la misma institución, donde ha participado en diversos proyectos sobre género, narrativas contemporáneas y cultura argentina. 
En el contexto del debate por la ley de Interrupción Voluntaria del Embarazo, que logró alcanzar tratamiento parlamentario en 2018, y tras una historia de décadas de luchas colectivas en contra de la violencia patriarcal y por una conquista de derechos fundamentales para las mujeres, ${ }^{1}$ la militancia feminista llegó a instalar el aborto en la sociedad y en la agenda política como un tema de salud pública. En ese marco, la movilización creciente de las mujeres y de los feminismos contribuyó a un mayor conocimiento de la situación de niñas y adolescentes que atraviesan embarazos, partos y maternidades en contextos de vulnerabilidad familiar y social. Cuando felizmente la ley de Interrupción Voluntaria del Embarazo fue aprobada en Argentina a fines de 2020, se había atravesado un extenso trayecto de luchas que, inscriptas en un linaje político feminista a lo largo de casi medio siglo, renovaron su fuerza desde el estallido del \#niunamenos en 2015 a través de la ocupación de las calles con movilizaciones multitudinarias, de pañuelazos masivos y de acciones militantes en las redes sociales, por donde circularon con fuerza consignas que se volvieron bandera: "Vivas nos queremos", "Que sea ley", "Se va a caer", "Niñas, no madres", "La maternidad será deseada o no será" y tantas otras.

$\mathrm{Al}$ calor de esta efervescencia política de la que parece tomar impulso, una serie de ficciones y de documentales realizados durante estos años inscribe un giro en las formas de figuración de la maternidad, en el cual cobra visibilidad la especificidad del momento histórico. En sintonía con las ideas y los acontecimientos que construyen un presente desde la revuelta y la marea feministas, reorganizando la escena pública a partir de la visibilización de demandas políticas sobre el derecho de las mujeres a decidir sobre sus cuerpos, películas como Niña mamá (Andrea Testa, 2019), Hogar (Maura Delpero, 2019), Alanis (Anahí Berneri, 2017), Mi amiga del parque (Ana Katz, 2015), Mala madre (Amparo Aguilar, 2019), Desmadre, fragmentos de una relación (Sabrina Farji, 2018), Mamá, mamá, mamá (2020), Las motitos (2020), entre otras, desmontan y ponen en cuestión el relato tradicional e idealizado de la maternidad para construir otras formas de figuración de maternidades diversas, plurales, fluidas. Este artículo propone un recorrido que, a través del análisis de algunas de estas películas, considerando otros antecedentes cinematográficos y haciéndolas dialogar con ejemplos literarios actuales, busca dar cuenta del ida y vuelta que tensiona las representaciones más allá de los bordes de la pantalla para imaginar nuevos "lugares de maternidad" (Domínguez 2007) que desacomodan los mandatos culturales al reinscribir la circulación del deseo, otras formas afectivas y el goce festivo de los cuerpos.

\section{Madres en cuadro}

A lo largo del siglo XX, el cine argentino despliega -y sostiene- un relato hegemónico de la maternidad según una concepción idealizada que organiza imaginarios, opera en los discursos institucionales y circula por la vida cotidiana, la cual asimila a la mujer con la madre como único destino posible, atribuyéndole un rol en la reproducción y en las tareas de cuidado familiar. En La vida imaginada. Vida cotidiana y cine argentino 1933-1970, Mario Berardi (2006) plantea que a principios de los años 30 se fue asentando un "modelo 
de lo femenino" en base a un reparto de roles entre una mujer decente -esposa y madreen el mundo privado versus una mujer "de la noche" vinculada al espacio público. El costumbrismo a menudo asociado al cine de géneros ( $\mathrm{y}$ al cine comercial en general) se apoya en esa idea de la madre como sostén de la organización doméstica, dedicada al cuidado de la casa y a la crianza de los hijxs dentro de un modelo de familia tradicional heteronormativa. Llevado al extremo de la abnegación y el sacrificio, el amor maternal incondicional define una figura particular en mujeres víctimas del destino o del azar que protagonizan -y dan nombre- a una vertiente del melodrama muy transitada en el período clásico: el melodrama de madre. En Puerta cerrada (Luis Saslavsky, 1939) Libertad Lamarque protagoniza a una madre que debe separarse de su pequeño hijo, a quien vuelve a ver luego de pasar veinte años en la cárcel, cuando morirá en su lugar para salvarlo. También la protagonista de Deshonra (Daniel Tinayre, 1952), acaba injustamente en la cárcel y morirá al dar a luz a su hijo. En Gente bien (Manuel Romero, 1939), una joven madre soltera que no puede conseguir trabajo para mantener al niño y se ve amenazada de perderlo, recibe la ayuda y la hospitalidad de un grupo de músicos para revertir la situación y para escarmentar al padre del chico. Entre los ejemplos más connotados, también se puede recordar Una mujer sin importancia (Luis Bayón Herrera, 1945), en el que Mecha Ortiz interpreta el papel de una madre soltera que logra salir adelante y, en cierta forma, dar vuelta el destino contra quien la abandonó en su juventud. ${ }^{2}$ El tópico de la madre soltera, el sacrificio y el sufrimiento por la separación del hijo cuentan a su vez con un antecedente en el período silente en Mi derecho, una película estrenada en 1920. Alejándose de las temáticas características del cine de la época, María B. de Celestini escribe y se cree que también dirige esta historia sobre una madre soltera que, para evitar la condena social, es llevada por su familia a ocultar su maternidad y es separada de su hijo, al que no puede olvidar y con quien se reencontrará pasados los años. ${ }^{3}$

Exactamente medio siglo más tarde, en 1970, haciéndose eco de la politización de la vida cotidiana en el contexto de la segunda ola del feminismo, un grupo de mujeres funda la Unión Feminista Argentina y organiza, ese mismo año, una campaña especial para el Día de la madre cuando salen a repartir (a "volantear") por las calles un folleto que denunciaba la injusta división sexual del trabajo y la explotación de las mujeres. Acompañada por la frase: "MADRE. Esclava o reina, pero nunca una persona", la gráfica mostraba a una madre agobiada por el "trabajo invisible" en las múltiples tareas domésticas y de cuidado de los hijxs dentro del hogar a la vez que la televisión le prescribía un mandato de belleza. La confección de este folleto había sido costeada por María Luisa Bemberg, que fue una de las fundadoras de la UFA en el mismo momento en que por primera vez se acercaba al cine, a partir de la escritura de un guion (el de Crónica de una señora, la película de Raúl de la Torre estrenada al año siguiente). Ese momento marca, entonces, un punto concreto de articulación entre feminismo y cine. Por un lado, en los hechos, porque el feminismo y la militancia, las reuniones de concienciación y de discusión con sus compañeras de la UFA, el aliento y el apoyo que se daban entre sí, fueron un impulso fundamental para que Bemberg avanzara por la senda del cine (como ella misma reveló en varias oportunidades), primero como guionista y luego también como cineasta. Y por el otro, porque en sus películas (tanto las que escribió como las que dirigió) hubo un gesto pionero que asumía 
la necesidad de revisar y deconstruir los lugares prefijados por la cultura patriarcal para las mujeres y las madres. Una preocupación que aparece de modo explícito a través de los diálogos de sus primeros guiones, al cuestionar cómo la educación maternal puede reproducir la opresión femenina: “¿Qué terrible que mujeres como vos eduquen así a sus hijas, que las contaminen!", recrimina a su madre interpretada por China Zorrilla en Triángulo de cuatro (Fernando Ayala, 1975), el personaje de Graciela Borges, quien en otra escena había declarado: "Si alguna vez tengo hijos, voy a educar a la chica como un varón y al varón como una chica".

En estas réplicas resuena la historia personal de la directora, ${ }^{4}$ que reprochaba a su madre ese tipo de educación: "[Mi madre] era una víctima, pero que se ocupaba de formar futuras víctimas. (...) Ella podría haberme animado a romper con mi medio. En cambio, se había convertido en custodia de los valores que habían cercenado su existencia" (Bemberg en Beccacece 1990: 9). No se trata meramente de un dato anecdótico, sino de cómo lo biográfico puede iluminar el horizonte colectivo de una época, en la cual, como recuerda Ann Kaplan:

El atractivo del feminismo residía precisamente en que proporcionaba un territorio para separarse de la intimidad opresiva de la madre; el feminismo era, en parte, una reacción contra nuestras madres, que habían intentado inculcarnos el elemento "femenino" patriarcal. El feminismo fue una oportunidad de averiguar quiénes éramos y que queríamos. Al margen de que fuéramos verdaderas madres, o no, llegábamos al feminismo como hijas, y hablábamos desde esa posición (1998: 307-308)

Desde esa posición de "hija" y en sintonía con sus ideas feministas, la maternidad en el cine de Bemberg aparece como un territorio generizado. En Señora de nadie (1982), Leonor (Luisina Brando) es una madre que decide marcharse de su casa, donde sus hijos seguirán viviendo junto al padre. Antes de irse, pega papelitos que señalan las tareas domésticas ("buscar traje azul tintorería" "descongelar", "buscar plomero", entre otras: el "trabajo invisible" que denunciaba el folleto de la UFA)- que ella ya no cumplirá. "No entiendo la maternidad", le dice Sor Juana a la virreina en Yo, la peor de todas (1990), al descubrir que esta se encuentra embarazada.

Virreina: ¿No sientes tristeza de haber renunciado a tener hijos?

Sor Juana: No. Los tengo (...) Mi telescopio. Mi reloj solar. Mi espejo de obsidiana, en que leo el pasado y vislumbro el futuro. Mi autómata. Mi astrolabio. Mi lira, tan antigua que me gusta pensar que la tocó el mismo Orfeo. Mis imanes. Mis plumas. Mis escritos, jestos son mis hijos!

Virreina: ¡Qué bella eres cuando te apasionas! Pero ¿sabés?, una mujer sin hijos es incompleta, no se puede negar la naturaleza.

Sor Juana: No todas somos iguales, señora. Algunas necesitamos la soledad. Soledad y silencio para poder pensar. 
En las tramas y en los personajes de estas películas se reconocen núcleos de interés del feminismo de aquellos años, como la desarticulación de una concepción romantizada de la maternidad que pasa por alto la sobrecarga de tareas que esta trae aparejada para las mujeres, o la idea de que ser madre no es el único camino para la realización personal de una mujer. "Las teorizaciones feministas - ha planteado Nora Domínguez- resultan en sí mismas opciones desde donde construir otras representaciones" (2007: 28). Sucede además que las mujeres "tienen una historia y una experiencia propia para aportar, que las coloca en un punto de partida diferente" (Marta Bianchi en Lukas 2003: 4), lo cual es especialmente determinante en el caso de la maternidad. No es casual que haya sido la primera mujer que logra filmar con regularidad dentro del cine profesional quien haya producido un deslizamiento en el relato hegemónico de la maternidad sostenido por la cultura también a través de los imaginarios que movilizan las películas, hasta entonces firmadas casi exclusivamente por varones. Porque, como explica Silvia Tubert, las representaciones, imágenes y figuras que crea el orden simbólico de la cultura están atravesadas por relaciones de poder que imponen discursos y prácticas en el ejercicio de ese poder por parte de los hombres sobre las mujeres (2009: 208).

Con la incorporación de las miradas y las voces de la generación joven de mujeres que empiezan a hacer cine cerca del cambio de milenio, nuevas representaciones, imágenes y figuraciones fueron transformando y dando otros matices a los mundos que entregan las películas, no necesariamente por los temas, sino por el hecho mismo de filmar. En ese sentido María Moreno decía que "un cuerpo de mujer producirá perogruyescamente imágenes de mujer" (1988: 35). Así, -advierte Clara Fontana- "a medida que las mujeres hacen cine, producen cine, dirigen cine, su propia toma de conciencia, por el enfrentamiento con el patrón cinematográfico vigente, está aportando un cambio en la concepción misma de los conflictos humanos" (1993: 8). Si en las primeras realizaciones de Lucrecia Martel, Albertina Carri, Ana Poliak, Sandra Gugliotta, Paula Hernández, Ana Katz, Verónica Chen -quienes toman la cámara en el contexto de renovación del Nuevo Cine Argentino-, la maternidad no fue un tema central, en años recientes, en cambio, las madres constituyen una figura protagónica en un conjunto muy diverso y amplio de producciones firmadas por algunas de ellas así como por directoras noveles, a la par de las nuevas voces de madres narradoras que en este mismo período aparecen en la literatura escrita por mujeres.

\section{Geografías corporales}

¿Qué es la maternidad? ¿Cómo se siente en el cuerpo? ¿Cuáles son sus tiempos, sus ritmos? ¿En qué cambia la vida? ¿De qué maneras se empieza a querer a un hijx? ¿Cómo se transforman los deseos? ¿Qué es un hijx? Estos interrogantes son desplegados de una y mil formas desde la voz de una madre joven, o no tan joven, que se pregunta qué es eso que vive, en un conjunto de obras literarias publicadas en los últimos años: Madre soltera (2013) de Marina Yuszczuk, Un beso perdurable (2017) de Gabriela Bejerman, Fugaz (2019) de 
Leila Sucari, A esta hora de la noche (2020) de Cecilia Fanti, entre otras. En estas obras, la experiencia de volverse madre (el embarazo, el alumbramiento, la vida con el bebé en los primeros meses, la relación con la propia madre) es narrada como un proceso en "presente perpetuo" (Roggero 2020: 257-258), escrito desde "el volcán de la experiencia" (la expresión es de Yuszczuk), con un énfasis intenso en la dimensión corporal, en cómo el cuerpo es afectado por esta experiencia. "Porque de última -Yuszczuk pregunta-, ¿adónde empieza un cuerpo, / y adónde termina? ¿De quién es / la teta en la boca de mi bebé? ¿Y de quién es / ese hueco que siento, o que me siento / cuando no esta囚 en mis brazos?” (2020 [2013]: 45). "Mi hijo es una cicatriz que no cierra. Me humedezco el dedo con saliva y la toco despacio. Soy un territorio lleno de novedades. La maternidad me cambió la geografía, me pierdo adentro de mí misma”, escribe Sucari (2019: 22). En un registro que integra recursos ficcionales y formas poéticas con lo autobiográfico, las voces maternas producen una reelaboración de motivos y figuras recurrentes en los textos: el parto, los cambios corporales y emocionales, el cansancio, los sueños, el dar la teta, la escritura.

La pregunta por el propio lugar en la escritura que habilita la maternidad define un punto de retorno en todas estas obras. En "Dar a luz", uno de los breves capítulos del libro citado, Gabriela Bejerman enlaza maternidad y escritura como dos zonas articuladas que requieren y comprometen el cuerpo: "Quiero contar el nacimiento de Cosme, aunque no voy a olvidarme nunca. Tecleo con él a upa, tiene cuatro semanas y media. Está dormido en la guagüita, por eso puedo escribir con las dos manos" (2017: 43). La escena de una escritura que procesa el cuerpo a cuerpo entre madre e hijx a través del deseo se contrapone a aquella otra imaginaria que Sor Juana invocaba en el filme de Bemberg, cuando defiende con una pregunta retórica su renuncia a la maternidad como opción de vida: “¿Hubiera sido más feliz (...) con niños trepados a mis faldas cada vez que busco una rima?”. En el siglo XXI, escritoras jóvenes sienten en la maternidad -incluso, paradójicamente, en lo que de ella no se puede contar- un impulso que moviliza el deseo de escribir. Como cuando Yuszczuk advierte: "yo parto de la base de que todo lo que está pasando no se puede escribir. Y sin embargo quiero decir algo" (2020 [2013]: 44).

$\mathrm{Si}$ en la literatura actual la voz de la madre narra experiencias, hilvana pensamientos y produce una reflexión sobre la propia maternidad, en el cine más reciente hay apenas contados ejemplos que asumen ese "tono confesional" (Roggero 2020: 260) a través, precisamente, de la inscripción de una voz narradora. Correspondencia (2020), por caso, presenta bajo la forma del ensayo fílmico una conversación epistolar filmada entre las jóvenes cineastas Dominga Sotomayor y Carla Simón, cada una a un lado del Atlántico (en Chile y en España). El cortometraje se organiza a partir de una serie de pasajes intercalados en los cuales las voces de una y otra reflexionan en torno a la historia familiar, la maternidad y el hacer cine, mientras el intercambio avanza con fotografías y filmaciones del archivo familiar, del entorno cotidiano y de un presente "suspendido" por la irrupción de la política como acontecimiento. Entre gestos que se reiteran desplazados en el tiempo, imágenes que emocionan, infancias evocadas en el recuerdo, sueños reveladores, se va tejiendo una trama donde la figuración de la maternidad queda enlazada con lo temporal, ya sea en los tiempos personales de la propia vida (“¿Es posible hacer cine y tener hijos?”, se pregunta Simón) o los de la urgencia política del presente ("Pensaba hablarte de esos niños corrien- 
do, de los hijos, pero aquí hay jóvenes muriendo", responde Sotomayor). No se trata, por cierto, de la experiencia de la maternidad sino del interrogante directo - "en bruto" - acerca de su posibilidad. La maternidad como una pregunta proyectada al futuro surge en el paso del tiempo entre generaciones de abuelas, madres e hijas; como se ve al comienzo del filme cuando la muerte de una abuela deja a una familia con dos generaciones, dado que todavía no hay niños, y Simón se pregunta entonces si habrá que crearlos. Si Correspondencia se inicia con una pregunta por lxs hijxs por venir, las imágenes con las que Sotomayor cierra el intercambio amplifican el alcance de la respuesta. La voz de la cineasta sentencia: "seguimos en dictadura", mientras jóvenes en las calles de Santiago en medio del estallido popular de 2019, donde fueron brutalmente reprimidxs con perdigones en los ojos, ${ }^{5}$ componen una escena que encuentra una clave de lectura en la visión esperanzada de su propia madre frente al horizonte de libertad que abría el plesbicito a fines de los 80 para el retorno de la democracia en Chile... como si en esto hubiera a su vez una respuesta sobre la maternidad: que puede comenzar con una decisión, o también con el futuro que una madre quiere dejarle a sus hijxs.

El legado materno se juega con otro sentido en Bloody Daughter (2012). Su directora, Stéphanie Argerich, explica de entrada por qué lleva el apellido de su madre, la célebre pianista mundialmente reconocida Martha Argerich, a quien favoreció la suerte cuando la moneda cayó de su lado para darle el nombre. Si la voz de la hija pone en marcha este documental que retrata a su madre a partir de la relación que las unió, en las primeras imágenes que se ven, no son los ojos de la joven desde donde se recorta el encuadre, dado que es ella quien se encuentra frente a la lente de la cámara, en el momento en que nace su segundo hijo. El dar a luz, el acto biológico por el que una mujer puede devenir madre, marca su posición de enunciación como hija. Dicho de otro modo: desde su maternidad puede mirar -y ser mirada- como hija con otros ojos: "No sé si el hecho de que ahora sea madre de algún modo cambia cómo ella me ve -dice-. Me da la impresión de que para ella sigo siendo un bebé. Pero a veces he sentido que es lo opuesto, que ella es el bebé que yo debo proteger".

Figurada a partir del antes (el trabajo de parto) y el después (el bebé llorando), la escena del nacimiento se representa a partir de una ausencia, de una imagen que falta. ¿Cómo se muestra un parto? ¿Quién puede contarlo? ¿Bajo qué regímenes de visibilidad? ¿Cuáles son las imágenes y los sonidos con los que se construye su representación? ¿Desde qué punto de vista es mostrado o narrado un nacimiento? En los ejemplos literarios analizados, el parto es un acontecimiento por excelencia que motoriza la escritura, aún desde la imposibilidad de ponerlo en palabras. "El parto no se puede contar, o mejor dicho, del parto no se puede contar nada que importe. Lo que te rompe y te destruye y te tira contra la vida salvaje desnuda y temblando es otra cosa", escribe Yuszczuk (2020 [2013]: 60). Ese resto de "vida" que resiste su representación en el lenguaje produce, paradójicamente, una figuración particular del acto de parir como una experiencia extrema e intensa de transformación, que es narrada desde la primera persona por una voz materna que hace jugar en su relato lo autobiográfico.

La impronta autobiográfica se desplaza desde la voz hacia la cámara (hacia la construcción de un encuadre y de un punto de vista como dispositivo de enunciación) en un ejemplo 
muy singular en la serie documental de cuatro capítulos La bella tarea que Albertina Carri y Marta Dillon realizaron para Contenidos Digitales Abiertos (CDA) en 2014. ${ }^{6}$ Sustrayendo por completo sus voces -es decir, sin recurrir al procedimiento de la voz over, que organiza un modo cinematográfico de narrar en primera persona emparentado con la literatura (como en Bloody Daughter, o en Correspondencia a través del género epistolar)-, lo que las realizadoras construyen es un dispositivo de escucha. Los testimonios reunidos (de embarazadas, madres, padres, obstetras, parteras, pediatras, ginecólogas y otrxs) se compaginan con una serie de imágenes de mujeres en el momento de parir. Incluso las de la misma Carri, aunque a diferencia de Stéphanie Argerich, es ella quien registra su propio parto, llevando esa posición de enunciación al extremo del límite corporal, cuando tiene que entregar la cámara a su compañera para poder continuar con "la bella tarea". En el caso de Carri, el acto de parir marca literalmente su posición de enunciación como madre. Como si en el doble carácter reflexivo de la acción que la imagen captura (parir, filmar) pudiera leerse una afirmación rotunda como respuesta a la pregunta de Simón (“¿Es posible hacer cine y tener hijos?") tomada al pie de la letra.

Si el cine suele representar el acto de parir sustrayendo una imagen y mostrando el antes y el después bajo una doble inscripción sonora que pasa del grito de la mujer al llanto del bebé, son esas imágenes siempre elididas en la pantalla, las de la experiencia corporal del alumbramiento, las que La bella tarea muestra una y otra vez, a partir de los relatos de las protagonistas. Son imágenes elocuentes y poco habituales, difíciles de ver, porque

están afuera del sistema: ni al cine ni a la tele ni al porno ni a la publicidad le sirven o le interesan, no entran en ningún canon, son imágenes salvajes, o decepcionantes, o intratables, porque no están armadas para ningún ojo. Nuestra cultura no tiene ojos para los partos. Será porque ahí no hay pose, y la estética no puede amansar hasta volver "lindos" esos momentos de entrañas, líquidos y caca (Yuszczuk 2014: online).

El procedimiento formal es la repetición, la figura es la saturación como un gesto estético que también es político. La escena de Penélope Cruz pariendo en un colectivo (al comienzo de Carne trémula de Pedro Almodóvar) con la que arranca el primer capítulo, da una pista de interpretación del contenido de la serie a favor del parto como un proceso fisiológico que sucede y que no necesita ser medicalizado. Condenando "los dictados de un modelo médico que les niega protagonismo [a las mujeres] y que con el argumento de estar cuidando de su salud, las sigue 'acostando' sin tener en cuenta sus deseos ni sus creencias, con menor o mayor delicadeza según sea su clase social, estado civil, edad, etnia y suerte" (Felitti 2011: 15), La bella tarea produce una intervención en la discusión sobre el derecho a un parto respetado y en contra de la violencia obstétrica, temas impulsados por la agenda feminista en las últimas décadas.? 


\section{Voces filmadas}

La pose define la relación de la cámara con los cuerpos femeninos de las series fotográficas que Adriana Lestido realizó a fines de los 80 y en la década siguiente: "Hospital Infanto Juvenil” (1986/1988), “Madres Adolescentes" (1988/1990), “Mujeres presas” (1991/1993), "Madres e hijas" (1995/1998). ${ }^{8}$ Hay un registro marcadamente testimonial en cómo estas fotografías en blanco y negro capturan imágenes de cuerpos en situación de vulnerabilidad desde "un impulso - de la mirada, de la cámara, de la toma- que busca hacerse presente y desaparecer", como ha precisado Nora Domínguez en un estudio sobre estas obras. ${ }^{9}$ "En los trabajos de Lestido se advierte una distancia de la mirada con su objeto, una distancia lograda y, a un tiempo, imperfecta" (2010: 63). Porque al intento de la fotógrafa de pasar desapercibida, de que su cámara interfiera lo menos posible, a su deseo de desaparición de la escena, lo "continúa del otro lado, del lado de la imagen, una política amorosa que retiene, fija cuerpos y movimientos femeninos, para singularizarlos en un encuadre y devolverlos a su lugar de residencia (...) barnizados por la pátina de una orfandad o soledad cargadas de afectos" (Domínguez 2010: 64). Estos ensayos fotográficos, su concepción estética despojada y respetuosa que asume una distancia amorosa como forma de acercarse humanamente a las mujeres retratadas, están en el origen de Niña mamá (2019), el documental de Andrea Testa que en cierta forma les rinde homenaje, al hacer funcionar las fotografías de madres adolescentes de Lestido "como un fuera de cuadro de la película", según afirmó la directora (en Martínez 2020: online).

La familiaridad entre los mundos narrativos de una y otra impacta desde las primeras imágenes en blanco y negro de una película que teje historias de vida de niñas y de adolescentes atravesadas por maternidades forzadas, por violencias, por el miedo de abortar clandestinamente, para componer una escena coral donde las mujeres aparecen despojadas de derechos y al margen de las políticas estatales de cuidado. Esas primeras imágenes presentan, en el consultorio de un hospital, a una chica de veinte años, con su cuarto bebé en brazos, mientras dice que quiere ligarse las Trompas. La figura de la joven domina el encuadre que la contiene casi en el centro de la imagen, mientras por el borde izquierdo apenas se insinúa, desenfocado, el contorno de la trabajadora social con quien conversa, que queda casi por completo afuera del campo. Ni una sucesión de planos bajo la dinámica habitual del campo-contracampo (codificada por la economía narrativa clásica como el modo convencional de filmar una conversación), ni el sentido de interpelación que podría generar un encuadre frontal que dejase sin figurar en la imagen, la inscripción del dispositivo técnico y de enunciación que la produce. La opción estética de Niña mamá está dada, en cambio, por la construcción de un espacio de escucha, sin "trucaje" (Bonitzer 2007), donde lo que acontece, lo que verdaderamente importa, es lo que cuentan las entrevistadas -su presencia, sus voces, sus historias-, a quienes Testa pone en escena como protagonistas y, al final, les dedica el filme: "Para ellas, para todas. Por nuestro derecho a decidir", se lee como cierre cuando terminan los créditos.

La disposición de los cuerpos y los rostros en el plano ensaya la fórmula visual de un distanciamiento amoroso. Como en las fotografías de Lestido, el punto de vista que organiza el encuadre está marcado por una toma de distancia pero también por la sensibilidad de 
una mirada que no busca apropiarse de las experiencias de las niñas mamá sino acompañarlas, tendiendo un lazo afectivo, de confianza. ${ }^{10}$ A esto responde la decisión formal de emplear solo una lente normal para filmar y no un zoom, ni tampoco micrófonos "corbateros": "La capacidad de acercarnos por sobre nuestros cuerpos no tenía que existir, ni siquiera -dice la cineasta-. No había una cercanía de ese tipo sobre el cuerpo de nadie. La cámara está y filma lo que filma" (en Martínez 2020: online). Testa descarta el efectismo emocional producido por la lógica televisivo publicitaria del zoom ("una gimnástica" que "no tiene nada que ver con la mirada", escribió alguna vez Serge Daney) y propone, en cambio, una puesta en escena de la duración a través del tiempo de una escucha que debe acontecer para comprenderse como necesaria. Por eso, el gesto del documental es darles tiempo a esas niñas dentro del plano. Niña mamá pone en tensión lo particular (figurado en la singularidad de cada rostro, de la gestualidad, del timbre de voz) con la universalidad del problema, la idea de que cada historia es una entre tantas otras - un sentido reforzado por la ausencia de carteles que identifiquen fechas o lugares, así como por la estética del blanco y negro y de los encuadres que, al repetir su disposición, unifican lo que muestran-. Desde la tensión entre la diversidad de versiones de una historia que es común para todas, el filme postula que la gestación es un tema social, no un secreto femenino.

\section{Figuras del desamparo}

El mismo año en que Testa realiza Niña mamá, se estrena Hogar (2019), una película de Maura Delpero que aborda la temática desde la ficción a través de una historia de madres adolescentes que viven con sus niñxs en un asilo de monjas. Hogar abre un nuevo registro para explorar los espacios institucionales de la maternidad, construyendo otra escena posible para figurar el desamparo de los cuerpos femeninos. Porque, si bien se trata de una ficción, hay un "tono documental" en la presencia corporal de las protagonistas que produce cierto desajuste, un corrimiento de la pura fábula. Si en los documentales previos que había realizado, la cineasta incorporaba elementos ficcionales, ${ }^{11}$ su primera obra de ficción trabaja, por el contrario, con un grado de "documentalidad" que intensifica la ficción. En los cuerpos de las jóvenes (que no son actrices y, en algunos casos, tuvieron experiencias cercanas a las narradas) hay un grado de verdad, que los emparienta con aquellos que Lestido había retratado en un hogar maternal o con los que Testa registra dentro de una institución hospitalaria. La presencia de esos cuerpos dentro del plano puede producir a veces un "estado de poesía", en el sentido que propone Tamara Kamenszain para caracterizar algunas novelas actuales: "Con 'estado de poesía' me refiero no a una retórica más elevada ni a un edulcorante manejo de las imágenes, sino a un punto de vista casi banal, si se quiere, donde la anotación sitúa a le sujete un paso más acá o uno más allá de la condición de personaje de ficción" (2020: 79-80). Con un tono delicado aunque no minimalista, Hogar apuesta a ese registro que se juega en pequeños deslices en los que la ficción se despega de la ficción y produce una forma de verdad. 
El filme retrata la vida dentro del asilo donde viven Luciana y Fátima con sus hijxs pequeños, al que llega Sor Paola, una monja joven que viene de Italia para tomar los votos perpetuos. En el ámbito del hogar conviven dos mundos, el de las chicas y el de las monjas (todas de edad avanzada y muchas de ellas ancianas), que se cruzan pero no se mezclan, ni siquiera cuando comparten el mismo espacio: cada uno tiene sus propios regímenes corporales, ritmos e intensidades diferentes, otros tiempos, distintas lenguas. La monja recién llegada es la que conecta esos mundos, al acercarse con afecto a las internas para ayudarlas en las tareas y con lxs niñxs. Así sucede cuando Luciana abandona el lugar y a su hija Nina durante varios días para ir a quedarse con un pibe, y ella le da cobijo a la niña, acompañándola por las noches, jugando a esconderse entre las sábanas, entre abrazos y amor. A medida que acontecen los encuentros entre Sor Paola y Nina, donde el cariño y el amor circulan a través del contacto entre los cuerpos -en contraposición al trato que Fátima establece con su hijo, al que cuida pero jamás acaricia ni abraza-, se va perfilando un interrogante sobre el ejercicio de la maternidad y sobre el amor maternal. ${ }^{12}$ Hogar irá transitando los pliegues y dobleces de la pregunta mediante distintas figuras que desacomodan los lugares de una respuesta fácil. “¿Vos que sabés del amor que yo le tengo a ella?”, se defiende Luciana cuando regresa y debe afrontar el hecho de que puede perder la custodia de Nina. Desde lo no dicho, lo que no se puede poner en palabras o se dice a media lengua, desde lo que sugiere un gesto, una mirada o un clima afectivo, van precipitando distintos sentidos del desamparo y la orfandad. ¿Qué siente Fátima por su mamá, cuya foto atesora, a pesar de que no la defendió frente a su novio (el de la madre) que -se da a entender- abusó de ella? ¿su hijo es de ese hombre? ¿por eso no puede acercarse al niño? Aunque nunca sea explicado, hay un pasado familiar de abandonos y desprotección que marca la precariedad de los cuerpos. En un capítulo de A esta hora de la noche en el que se pregunta de cuántas maneras se extraña a una madre, Cecilia Fanti reflexiona sobre el lugar protagónico de la madre ausente (en su caso, muerta) en la propia maternidad, estableciendo una continuidad generacional: "convertirse en madre, pensarse como hija, transitar ese pasaje, ocupar otro lugar" (2020: 105). Un pasaje difícil que a veces se hace a los tumbos, como en el caso de Luciana y de Fátima, o de las niñas de la película de Testa, que ya son madres sin haber podido ser todo lo hijas que necesitaban. ${ }^{13}$

En el caso de las monjas, el amor de "madres espirituales" define una figuración materna inscripta en el cristianismo, que -como apunta Julia Kristeva- "es la construcción simbólica más refinada en la que la femineidad (...) se restringe a lo Maternal” (1988: 209). En el momento en que está por consagrarse a Dios, Sor Paola, por su relación con Nina, pareciera dudar de ese destino. ¿Acaso desea ser madre? ¿alguna vez lo ha deseado? ¿Cómo surge el deseo de la maternidad? ¿es una certeza, o es una duda? ¿puede ser que a veces sea -como especula Yuszczuk- "un deseo tan profundo que no se sabía, y el cuerpo se adelanta y lo realiza”? (2020 [2013]:11). Hacia el final, cuando se sabe que Luciana tendrá que dejar el asilo y quedará a disposición de un juez, acontece uno de los pasajes más bellos de la película, el único que transporta la mirada hacia el exterior en la ciudad. Sor Paola, sin el velo, se va por las calles con Nina dormida en brazos, deambula, duda en subir a un colectivo, se sienta en un umbral; como si no pudiera o no quisiera dejarla ir hacia un 
futuro que será cruel. Desde la ventanilla del taxi que finalmente se lleva a madre e hija de ese ámbito que, a pesar de todo, fue de cobijo, la mirada de Luciana, en el último plano del filme, es desoladora.

El tópico de la mala madre ${ }^{14}$ tiene otra deriva en Alanis (2017) de Anahí Berneri, con la que Hogar arma una serie a partir de la figuración del espacio y la idea de comunidad. Ese mundo del afuera -las calles, la noche, la intemperie- que Hogar deja fuera de campo, es el que habita el personaje de Sofía Gala en la película de Berneri donde, actuando con su propio bebé, encarna a una joven madre y prostituta. En ambos casos, el afuera es el espacio de la sexualidad y el deseo, adonde Alanis intenta encontrar clientes cuando es desalojada del departamento en el que vive y trabaja junto a una amiga, y adonde se escapa Luciana para estar (sexualmente) con el pibe que, por segunda vez, la terminará golpeando. El eje madre-prostituta conjuga dos campos semánticos, maternidad y sexualidad, que la cultura patriarcal siempre intenta separar, como mostraban las teóricas feministas décadas atrás en sus abordajes críticos del cine clásico hollywoodense. Por ejemplo, el trabajo que Ann Kaplan dedicó a La venus rubia de Josef von Sternberg, en el que analiza el papel de Marlene Dietrich y advierte "la contradicción fundamental entre el fetichismo y la maternidad que constituye la base de toda la película" (1998 [1983]: 103). En este sentido, La venus rubia es un antecedente clave en relación con Alanis, en una doble dimensión: por un lado, la figuración fílmica de la madre sexualizada y, por otro, la articulación entre espacio y maternidad, que plantea el itinerario de huida del personaje de Dietrich con su hijo a cuestas, escapando del peso de la ley patriarcal (de su marido y de la policía). “Puede una madre ser nómada?", sería entonces la pregunta -tomando los términos precisos en los que la formula Julia Kratje (2014: 12) al estudiar figuraciones fílmicas de la maternidad en el cine latinoamericano-. El relato seguirá el trayecto de Alanis con el bebé, andando por las calles y viviendo de prestado, hasta que al final encuentra un nuevo "hogar" y compañeras de trabajo. "Andá tranquila, que con tanta teta no te va a extrañar", le dice una de ellas cuando debe ir a recibir a un cliente. Si la intemperie, el nomadismo, la falta de cobijo desorganizan las experiencias de la maternidad, en las formas de hacer comunidad que propone Alanis, y también Hogar, son posibles otros cuidados, otras maneras de maternar.

\section{Madre no hay una sola}

Casi medio siglo después de que mujeres de la Unión Feminista Argentina salieran a las calles un Día de la Madre para repartir folletos que denunciaban la opresión de las mujeres en el hogar, en las vísperas de la celebración de esa misma fecha en 2018, en el contexto de un año clave de demandas y movilizaciones feministas, circuló por las redes sociales un spot, titulado Mala madre, que se viralizó. El video, de menos de dos minutos, se dirige a las mujeres que no se identifican con los estereotipos de madre que presentan a diario las publicidades y los medios de comunicación, y que están, en cambio, en ese "Lado B", el de las "Malas madres", que el corto reivindica haciendo referencia a un conjunto heterogéneo de posiciones subjetivas asociadas al ejercicio cotidiano de la maternidad y a la decisión 
de ser madre o de no serlo. ${ }^{15}$ La pieza condensa en una serie de figuras y de situaciones la transformación viva de todo un imaginario. Del mismo modo -como mostré a lo largo de este trabajo-, madres jóvenes, adolescentes, niñas, prostitutas, "malas madres", madres afectivas, vienen ocupando un lugar protagónico en un conjunto amplio y muy diverso de obras fílmicas, audiovisuales y literarias, cuyos mundos sensibles despliegan un estado de la imaginación sobre el presente.

Silvia Tubert enseña que "las representaciones o las figuras de la maternidad, lejos de ser un reflejo o un efecto directo de la maternidad biológica, son producto de una operación simbólica que asigna una significación a la dimensión materna de la femineidad y, por ello, son al mismo tiempo portadoras y productoras de sentido" (2009: 208-209). En tanto dispositivo que registra cuerpos dispuestos en un espacio y en un tiempo, el cine tiene determinadas formas de construir y de atravesar las tramas y los relatos de una época, metabolizando sentidos provenientes de la realidad (Amado 2009: 43), ya sea para afirmarlos, desestabilizarlos o subvertirlos. Género, identidad sexual, edad, clase social, etnia son algunas variables que modulan diferentes experiencias de la maternidad que el cine argentino de este siglo ha comenzado a procesar en sintonía con las preguntas que abre la revuelta feminista del presente, en sus tramas y en sus imágenes, en los mundos que presenta, en los cuerpos que pone en escena y hace escuchar, construyendo nuevas figuras de madres que desacomodan sus formas más tradicionales y estabilizadas. La diversidad de estas figuras pone en cuestión la fijeza del rol maternal, desafiando mandatos culturales que sostienen un modelo prefijado de ser madre y de ser mujer. Es un dato elocuente en ese sentido la insistencia del significante materno en los títulos de las películas, como si el término necesitara expandir su significado para expresar la diversificación que se ha producido en aquello que nombra. Maternidades fluidas, abiertas, plurales configuran nuevos lugares para las madres en los mundos que el cine quiere imaginar.

\section{Notas:}

1. En Cuando el feminismo era mala palabra. Algunas experiencias del feminismo porteño, Mónica Tarducci, Catalina Trebisacce y Karin Grammático (2019) presentan una historia del feminismo argentino de la segunda ola (de los años 70 a los 90), que hace hincapié en las continuidades entre las luchas de las mujeres de entonces y los reclamos del presente.

2. Un estudio sobre el melodrama en el cine argentino que historiza el género y repasa con exhaustividad los corpus clásicos entre los 30 y los 50 se encuentra en el trabajo de Ricardo Manetti "El melodrama, fuente de relatos. Un espacio artístico para madres, prostitutas y nocheriegos melancólicos" (2000).

3. Esta película, como casi la totalidad del cine argentino del período silente, se encuentra perdida. Sigo la investigación de Lucio Mafud (2016) quien ha reconstruido el cine del período a partir del estudio de materiales de prensa y fuentes de la época.

4. Bemberg, que no había recibido una educación formal como sus hermanos varones, lo cual siempre le pesó, llegó al cine cuando sus cuatro hijxs ya eran grandes, o sea, luego de 
cumplir con los mandatos de género como madre, según manifestó. Acerca de la historia familiar de la directora, en relación con su profesión y con su trayectoria, se pueden ver los trabajos de Leila Guerriero y de Julia Montesoro en El asombro y la audacia. El cine de María Luisa Bemberg, compilado por Julia Kratje y Marcela Visconti (2020).

5. La revuelta social estalló el 18 de octubre de 2019 cuando estudiantes secundarios llamaron a evadir el pago del transporte público, lo cual dio lugar a grandes movilizaciones en contra de la administración neoliberal instalada en la dictadura de Pinochet y sostenida por décadas hasta hoy.

6. Agradezco a Julia Kratje la referencia a la serie de Carri y Dillon, así como la lectura de este trabajo.

7. Cabe recordar que, en el contexto de ampliación de derechos relacionados con la gestación, el parto y la crianza, en las últimas décadas se sancionaron la Ley de Parto Humanizado (2004) en defensa de los derechos de madres, padres e hijos en el momento del nacimiento, para limitar el intervencionismo médico no justificado, y la Ley de Protección Integral para Prevenir, Sancionar y Erradicar la Violencia contra las Mujeres en los Ámbitos en que se Desarrollen sus Relaciones Interpersonales (2009), que condena la violencia obstétrica (entre otros tipos de violencia), entendida como "aquella que ejerce el personal de salud sobre el cuerpo y los procesos reproductivos de las mujeres, expresada en un trato deshumanizado, un abuso de medicalización y patologización de los procesos naturales". Otra cuestión muy presente en el documental, que también está siendo pensada desde el feminismo, son las significaciones políticas del parto domiciliario. Sobre este tema puntual se puede ver el trabajo de Valeria Fornes (2011).

8. Estos trabajos, junto a la serie El amor (1992/2005), formaron parte de la retrospectiva Lo que se ve. Fotografías 1979/2007, realizada en el Centro Cultural Recoleta de la ciudad de Buenos Aires entre el 11 de marzo y el 20 de abril de 2008, con curaduría de Gabriel Díaz y Juan Travnik.

9. El mismo integra un dossier sobre fotógrafas organizado por esta autora para el volumen 16 de la revista Mora, publicado en diciembre de 2010.

10. En el extremo exactamente opuesto de la ética de la representación que sustenta las elecciones formales de la película de Testa en función del respeto y el cuidado de las entrevistadas, de sus historias, de sus voces y del lugar que ocupan en la imagen, se encuentra la operación de manipulación y la instrumentalización de la fotografía de una niña que acompañó el editorial publicado por el diario La Nación el 1 de febrero de 2019. Bajo el título "Niñas madres con mayúsculas", el texto sostenía provocadoramente la existencia del "instinto materno" como estrategia de defensa del derecho de las niñas violadas a ser madres. En un análisis perspicaz de esa fotografía tomada de un banco de imágenes (dado que la misma había sido utilizada previamente por el diario para ilustrar una nota con un sentido distinto), Carlos Masotta considera algunos antecedentes de la relación miradaviolación en la pintura del renacimiento y del barroco y explica:

En la foto, el corrimiento del violador del campo de visión deja el centro al cuerpo de la niña como objeto de exposición desplazando al primero al invisible espacio de la impunidad. Ninguna de aquellas pinturas había llegado a 
tanto. Ninguna de esas representaciones que martillaron con la combinación de erotismo y violencia sobre las mujeres, recrearon el punto de vista desde la posición de un violador de niñas. Hubo que esperar al siglo XX y, en especial, al XXI con su voraz mirada de cámara de seguridad, de selfie, de dron y de GoPro para lograr esa imagen. Por supuesto, no es algo exclusivamente tecnológico ni visual. El resto lo hace el conservadurismo sin bozal en auge (2020: 221).

La intervención de Masotta forma parte de un debate coordinado por Débora Daich (2020), "Niñas, no madres", en el que se presenta un panorama regional muy bien informado sobre el problema de las maternidades precoces. Disponible en: http://genero. institutos.filo.uba.ar/publicacion/debate-ni\%C3\%B1as-no-madres

11. Signori professori (2008) es su primer largometraje, en el que indaga en el mundo de la enseñanza a través de los pensamientos, estados de ánimo y sentimientos de tres profesores. El mediometraje Nadea e Sveta (2011) presenta la historia de dos mujeres de Moldova que emigran a Italia en busca de trabajo, dejando a sus hijos, familia y amigos en su país, que siempre estará presente en el futuro que intentan forjar.

12. Maternal fue el título con el que la película circuló en el exterior, donde se estrenó en la competencia internacional del Festival de Locarno en 2019.

13. Un caso distinto, que recupera en la figura de la madre una posibilidad de reparación, está en Las motitos (Inés María Barrionuevo y Gabriela Vidal, 2020), una ficción que narra la historia de una chica de catorce años que queda embarazada de su novio y quiere abortar, lo cual finalmente logra hacer, de forma "segura", gracias a la ayuda de su madre -que así evita, acaso, que se repita su propia historia-. La escena en que la madre se entera del embarazo, tiene lugar en medio de una reunión con sus amigas, en una terraza, tomando cerveza, fumando marihuana, cantando, bailando, divirtiéndose como cuando eran adolescentes... como si fuera esa posibilidad de disfrutar, de sentirse libre, lo que quiere que su hija no pierda. Es lo que sugiere la escena final, cuando la chica se pone al manubrio de "la motito", decide el rumbo y maneja con libertad por una autopista, en una versión que actualiza en clave femenina y feminista las imágenes de Rapado que décadas atrás inauguraban una nueva forma estética para el cine argentino.

14. Mala madre se llamó un documental estrenado en 2019 en el que Amparo Aguilar, a través de testimonios de mujeres y de su propia experiencia como madre, busca desarticular el ideal de la "buena madre". Esta cuestión aparece con otros matices en Mi amiga del parque (Ana Katz, 2015), una película que transita todos los tópicos de la maternidad, incluido el de la "mala o buena madre", tematizado a través de la culpa que siente una madre joven, por no haber podido dar la teta a su bebé, cuya llegada ha desorganizado su vida. También, en una variante muy interesante, a través del personaje de la "amiga del parque", quien ejerce una suerte de comaternidad con la hermana, que le dejará a su beba cuando se mude a otra ciudad con un novio. Katz construye la situación sin tonos melodramáticos, incluso con humor, y sin juzgar a los personajes.

15. El spot, que fue realizado por encargo para la firma cordobesa de ropa de "todos los talles" Tomas \& Anouk, se puede ver acá: https://www.youtube.com/watch?v=E8fleWNkQVE 


\section{Bibliografía}

Amado, A. (2009). La imagen justa. Cine argentino y política (1980-2007). Buenos Aires, Colihue.

Beccacece, H. (1990). "La conquista de una identidad”, Entrevista a María Luisa Bemberg, revista La Nación, 4 de marzo, pp. 6-11.

Bejerman, G. (2017). Un beso perdurable. Buenos Aires, Rosa Iceberg.

Berardi, M. (2006). La vida imaginada. Vida cotidiana y cine argentino 1933-1970. Buenos Aires, Del Jilguero.

Bonitzer, P. (2007). [1982] “Los fragmentos de la realidad”, en El campo ciego. Ensayos sobre el realismo en el cine. Buenos Aires, Santiago Arcos, pp. 81-93.

Daich, D. (2020). "Niñas, no madres", Mora, Revista del Instituto de Investigaciones en Estudios de Género, Nro. 26, Universidad de Buenos Aires. También disponible en: http:// genero.institutos.filo.uba.ar/publicacion/debate-ni\%C3\%B1as-no-madres

Domínguez, N. (2010). "Mirar madres. Adriana Lestido: espacios, rostros, afectos", Mora, № 16, Revista del Instituto de Investigaciones en Estudios de Género, pp. 61-80.

Domínguez, N. (2007). De dónde vienen los niños. Maternidad y escritura en la cultura argentina. Beatriz Viterbo, Rosario, 2007.

Fanti, C. (2020). A esta hora de la noche. Buenos Aires, Rosa Iceberg.

Felitti, K. (coordinadora) (2011). Madre no hay una sola. Experiencias de maternidad en la Argentina. Buenos Aires, Ciccus.

Fontana, C. (1993). María Luisa Bemberg. Buenos Aires, Centro Editor de América Latina.

Fornes, V. (2011). "Parirás con poder... (pero en tu casa). El parto domiciliario como experiencia política contemporánea", en Felitti Karina (coordinadora) Madre no hay una sola. Experiencias de maternidad en la Argentina. Buenos Aires, Ciccus.

Kamenszain, T. (2020) Libros chiquitos. Buenos Aires, Ampersand.

Kaplan, A. (1998) [1983]. Las mujeres y el cine. A ambos lados de la cámara. Madrid, Cátedra.

Kratje, J. (2014). "Las periferias del paraíso, los dilemas de la culpa. Figuras heterogéneas de la maternidad en el cine latinoamericano contemporáneo", Mora. Revista del Instituto de Investigaciones en Estudios de Género, Nro. 20, pp. 5-17.

Kratje, J. y Visconti, M. (comps.) (2020). El asombro y la audacia. El cine de María Luisa Bemberg. Buenos Aires, Festival Internacional de Cine de Mar del Plata/INCAA.

Kristeva, J. (1987). “Stabat Matter”, Historias de amor. México, Siglo XXI.

Lestido, A. (2008). Lo que se ve. Fotografías 1979/2007. Catálogo de la muestra realizada en el Centro Cultural Recoleta, Buenos Aires, marzo-abril.

Lukas, A. (2003). "Estoy comprometida con este ciclo más que con mi carrera de actriz", Entrevista a Marta Bianchi. El Festival a Diario. 18 Festival Internacional de Cine de Mar del Plata. Domingo 9 de marzo.

Mafud, L. (2016). La imagen ausente. El cine mudo argentino en publicaciones gráficas. Catálogo. El cine de ficción (1914-1923). Buenos Aires, Biblioteca Nacional de la República Argentina / Teseo. 
Manetti, R. (2000) "El melodrama, fuente de relatos. Un espacio artístico para madres, prostitutas y nocheriegos melancólicos", en España Claudio (director) Cine argentino. Industria y clasicismo (1933/1956), Buenos Aires, Fondo Nacional de las Artes.

Martínez, L. (2020) “Niña Mamá: una película que grita ¡Que sea Ley!”, Latfem, 17 de noviembre. Disponible en: https://latfem.org/nina-mama-una-pelicula-que-grita-que-sea-ley/

Masotta, C. (2020) "La mirada de Acteón", en Debate "Niñas, no madres", Mora, Revista del Instituto de Investigaciones en Estudios de Género, Nro. 26, 221-222.

Moreno, M. (1988) “Salir de la cámara, tomar la cámara”, en Catálogo Primer Festival Internacional de Cine Realizado por Mujeres La mujer y el cine, 1 al 8 de abril.

Roggero, J. (2020) “Lo materno: espacio continuo, presente perpetuo", en Arnés Laura, De Leone Lucía y María José Punte (coordinadoras) En la intemperie: poéticas de la fragilidad y la revuelta, tomo $\mathrm{V}$ de Historia feminista de la literatura argentina, colección dirigida por Laura Arnés, Nora Domínguez y María José Punte. Villa María, Eduvim, pp. 257-261.

Sucari, L. (2019) Fugaz. Buenos Aires, Tusquets.

Tarducci, M.; Trebisacce, C. y Grammático, K. (2019). Cuando el feminismo era mala palabra. Algunas experiencias del feminismo porteño. Buenos Aires, Espacio Editorial.

Tubert, S. (2009). "Maternidad”, en Gamba Susana Beatriz (coordinadora), Diccionario de estudios de género y feminismos. Buenos Aires, Biblos.

Yuszczuk, M. (2020). Madre soltera y otros poemas. Buenos Aires, Blatt \& Ríos.

Yuszczuk, M. (2014). "Parirás con placer”, Suplemento Las 12, Página 12, 31 de octubre. Disponible en: https://www.pagina12.com.ar/diario/suplementos/las12/13-9274-201410-31.html

\section{Filmografía}

Alanis (Anahí Berneri, 2017)

Bloody Daughter (Stéphanie Argerich, 2012)

Correspondencia (Dominga Sotomayor y Carla Simón, 2020)

Crónica de una señora (Raúl de la Torre, 1971)

Deshonra (Daniel Tinayre, 1952)

Desmadre, fragmentos de una relación (Sabrina Farji, 2018)

Gente bien (Manuel Romero, 1939)

Hogar (Maura Delpero, 2019)

La bella tarea (Albertina Carri y Marta Dillon, 2014)

Las motitos (Inés Barrionuevo y Gabriela Vidal, 2020)

Mala madre (Amparo Aguilar, 2019)

Mamá, mamá, mamá (Sol Berruezo Pichon-Rivière, 2020)

Mi amiga del parque (Ana Katz, 2015)

Mi derecho ([María B. de Celestini y/o Roberto Biasotti], 1920)

Niña mamá (Andrea Testa, 2019) 
Puerta cerrada (Luis Saslavsky, 1939)

Señora de nadie (María Luisa Bemberg, 1982)

Triángulo de cuatro (Fernando Ayala, 1975)

Una mujer sin importancia (Luis Bayón Herrera, 1945)

Yo, la peor de todas (María Luisa Bemberg, 1990)

\begin{abstract}
If, over the course of the $20^{\text {th }}$ century, Argentine cinema deployed and upheld an hegemonic narrative of maternity based on an idealized conception which organizes worldviews, works on institutional discourses, and finds its way into everyday life, well into the new millennia, a series of works of fiction and documentaries has effected a change in the ways of portraying mothers, in which the specific aspects of the historical moment become evident. In line with the ideas and the events which make up the current time, since the feminist revolts and the feminist tide which erupted in Argentina in 2015, reorganizing the public scene through the visibilization of political demands about women's rights to decide over their own bodies, films like Hogar (Maura Delpero, 2019); Niña mama (Andrea Testa, 2019); Alanis (Anahí Berneri, 2017); Mi amiga del parque (Ana Katz, 2015); Mala madre (Amparo Aguilar, 2019); Desmadre, fragmentos de una relación (Sabrina Farji, 2018); Mamá, mamá, mamá (Sol Berruezo Pichon-Rivière, 2020); Las motitos (Inés Barrionuevo y Gabriela Vidal, 2020), among others, create a displacement and challenge the traditional narrative enshrining motherhood as a woman's only possible fate. At what time and how does the revolt channel itself into creative expression and its various ways of crafting stories, inventing figures, and producing meaning? Through the analysis of some of the aforementioned examples, this works attempts to explain the bidirectional forces stressing the representations beyond the boundaries of the screen to imagine new "places of maternity" (Domínguez 2007) which disrupt the cultural imperative by reinscribing the circulation of desire, other forms of affection, and the festive enjoyment of bodies.
\end{abstract}

Keywords: maternity - women's cinema - contemporary Argentine cinema - feminist film critique - green tide.

Resumo: Se ao longo do século XX, o cinema argentino exibe e sustenta uma história hegemônica da maternidade segundo uma concepção idealizada que organiza o imaginário, opera nos discursos institucionais e circula no cotidiano, no final do novo milênio, uma série de ficções e de documentários inscreve uma virada nas formas de figuração das mães, nas quais a especificidade do momento histórico torna-se visível. Em sintonia com as ideias e acontecimentos que constroem um presente desde a revolta e a maré feminista que eclodiu na Argentina em 2015, reorganizando a cena pública a partir da visibilidade das demandas políticas sobre o direito da mulher de decidir sobre seu corpo, filmes como A Casa (Maura Delpero, 2019); Menina Mãe (Andrea Testa, 2019); Minha amiga do par- 
que (Ana Katz, 2015); Mãe má (Amparo Aguilar, 2019); 'Desmadre', fragmentos de um relacionamento (Sabrina Farji, 2018); Mãe, mãe, mãe (Sol Berruezo Pichon-Rivière, 2020); As Motinhos (Inés Barrionuevo y Gabriela Vidal, 2020), entre outros, produzem um deslocamento, e problematizam, a história tradicional que assimila a mulher com a mãe como único destino possível. Em que momento e de que forma a revolta continua nas expressões criativas e nas suas formas de construir histórias, inventar figuras, produzir sentidos? Por meio da análise de alguns dos exemplos fílmicos mencionados, meu trabalho busca dar conta das idas e vindas que enfatizam as representações além das bordas da tela para imaginar novos "lugares de maternidade" (Domínguez 2007) que rompem mandatos culturais ao reinscrever a circulação do desejo, outras formas afetivas e a fruição festiva dos corpos.

Palavras chave: maternidade - cinema feminino - cinema argentino contemporâneo - crítica de cinema feminista - maré verde.

[Las traducciones de los abstracts fueron supervisadas por el autor de cada artículo] 